ISSN: 2238-8052

\title{
DESCOLONIZAR E COMPREENDER A QUESTÃO INDIGENA COMO APORTE AOS ESTUDOS GEOGRÁFICOS
}

\author{
DESCOLONIZAR Y COMPRENDER LA CUESTIÓN INDIGENA COMO APORTE A LOS ESTUDIOS \\ GEOGRÁFICOS
}

\author{
Beatriz Barbosa da SILVA ${ }^{1}$ \\ Claudio Ubiratan GONÇALVES²
}

Ensaio recebido em 27/09/2017 e aceito em 29/11/2017

Palavras-chave:

Questão indígena Comunidade Geografia agrária Colonialidade Território

Palabras clave: Cuestión indígena Comunidad Geografía agraria Colonialidad Territorio

\section{R E S U M O}

0 trabalho trata as dificuldades de abordagem existentes e que envolve a questão do indígena no Brasil, principalmente, no âmbito da Geografia. Aponta a necessidade de uma ampliação dos estudos nessa temática, uma vez que possibilitaria esclarecer aspectos ainda não discutidos por outras disciplinas como antropologia, sociologia e área das ciências da saúde. Apresenta a questão indígena como atual e necessária dentro do debate geográfico, pois, o território passa a ser apreendido como forma concreta de defesa e resistência da identidade sociopolítica. Ou seja, o território indígena como espaço de reprodução da vida e das múltiplas culturas e da alteridade a partir do metabolismo com a natureza. Neste sentido a cultura passa a ser a chave explicativa na compreensão da retomada dos territórios e a principal forma de resistência das comunidades e de seus modos de vida.

\section{R E S U M E N}

El articulo trata las dificultades de abordaje existentes y que involucra la cuestión del indígena en Brasil, principalmente, en el ámbito de la Geografía. Se plantea la necesidad de una ampliación de los estudios en esta temática, ya que posibilitaría esclarecer aspectos aún no discutidos por otras disciplinas como antropología, sociología y área de las ciencias de la salud. Se presenta la cuestión indígena como actual y necesaria dentro del debate geográfico, pues el territorio pasa a ser aprehendido como forma concreta de defensa y resistencia de la identidad sociopolitica. Es decir, el territorio indígena como espacio de reproducción de la vida y de las múltiples culturas y de la alteridad a partir del metabolismo con la naturaleza. En este sentido la cultura pasa a ser la clave explicativa en la comprensión de la reanudación de los territorios y la principal forma de resistencia de las comunidades y de sus modos de vida.

\footnotetext{
1 Departamento de Ciências Geográficas da Universidade Federal de Pernambuco. Correio eletrônico: biabarbosa42@gmail.com.

2 Professor Associado do Departamento de Ciências Geográficas da Universidade Federal de Pernambuco. Correio eletrônico: biragrario@gmail.com.
} 


\section{CONSIDERAÇÕES INICIAIS}

Ao se abordar a questão indígena no Brasil por meio de uma visão geográfica, é possível perceber os conflitos territoriais e as problemáticas socioambientais e culturais inseridas nessas comunidades. A mistificação da figura do índio e a reprodução da colonialidade são realidades presentes na sociedade e refletidas em muitos estudos que se referem aos povos tradicionais. 0 movimento indígena representa um símbolo de resistência e da luta pelo direito à autonomia. A resistência das populações nativas passa pela apropriação do conhecimento, território e autoidentificação. É através da compreensão das problemáticas presentes na realidade dessas sociedades, que há o processo de desconstrução de ideologias que tentam deslegitimar a luta originária.

Dito isso, abordaremos a temática a partir de três dimensões essenciais para os estudos geográficos dos povos tradicionais: o território, a natureza e a cultura. Tendo como base os estudos de Andre Araújo, Emerson Guerra e Sandoval Amparo, geógrafos que discutem sobre as comunidades indígenas, em especial as do Brasil, através de suas relações e conflitos, busca-se fornecer uma visão geral das populações originárias, através de uma perspectiva geográfica. É necessária a produção de conteúdos que compreendam a realidade indígena e as particularidades de cada povo, assim como os conflitos presentes em seus territórios.

\section{QUESTÃO INDÍGENA COMO QUESTÃO GEOGRÁFICA}

Os conflitos territoriais indígenas englobam, além da luta pelo direito à reprodução de suas culturas e crenças, problemáticas que envolvem as questões ambientais, sociais e políticas das quais são sujeitos. Compreender as reivindicações dos povos tradicionais como uma luta que não se restringe apenas a terra é um primeiro passo para a compreensão de sua realidade social.

Apesar da conquista do movimento indígena com a Constituição de 1988, a burocracia presente nos processos demarcatórios tem como conseqüência um crescimento no número de demandas das comunidades reivindicando sua demarcação e que ficam vulneráveis a violência de posseiros e outros agentes interessados na região. De acordo com o relatório de 2015 da Comissão dos Indigenistas Missionários (CIMI) sobre a violência contra os povos indígenas, das 1.113 terras indígenas em território nacional, 58,7\% ainda aguardam a finalização dos seus processos demarcatórios e outros $26 \%$ das terras encontram-se na fase de identificação. Com a promoção de políticas e conhecimentos que têm como objetivo deslegitimar a luta do movimento indígena, os povos tradicionais são vítimas da violência e preconceitos promovidos pelos mesmos atores responsáveis pela demarcação dos seus territórios. Através de dados da Comissão Pastoral da Terra (CPT) de 2016 é possível perceber o crescimento dos conflitos pelo território originário: em 2008 foram identificados 
59 conflitos, já em 2015 os conflitos passaram para 100, demonstrando o aumento do número de ataques e o cenário de agressão a que essas populações são submetidas.

Os debates construídos e reproduzidos pela mídia hegemônica, assim como a adoção de políticas compensatórias, inserem problemáticas menores com a intenção de invisibilizar a realidade social dos povos tradicionais e fragilizar o movimento. Esse processo ideológico de construção da imagem das sociedades originárias através de moldes coloniais e em função do colonizador (ARAÚJO, 2011) é uma das principais formas de violência contra essas comunidades, e tem como objetivo central deslegitimar a luta e enfraquecer as organizações de apoio e mediação do movimento indígena, como a criminalização da FUNAI, utilizando por base preconceitos e concepções etnocêntricas.

A estruturação do pensamento moderno-colonial não se restringe a política e a mídia, mas se reflete na composição de estudos sobre os povos originários. $O$ índio é concebido através de uma lente eurocêntrica, uma visão folclórica e romantizada, vinculado à figura do selvagem. "Los nativos serían ingenuos y maliciosos, pacíficos y caníbales, en definitiva, romantizados y odiados" (ARAÚJO, 2011, p.33).3.

A condição de "ser indígena" torna-se sinônimo de "ser atrasado", viver na idade da pedra (CORREIA, 2005). Os povos indígenas são homogeneizados, virando uma única massa aprisionada no passado, suprimindo a diversidade e particularidade de cada povo e estabelecendo o conceito de evolução segundo os padrões europeus, o que os coloca na condição de inferiores e apresenta a noção de desenvolvimento como "solução".

Contudo, de acordo Porto-Gonçalves (2011, p.39)

Des-envolver é tirar o envolvimento (a autonomia) que cada cultura e cada povo mantém com seu espaço, com seu território; é subverter o modo como cada povo mantém suas próprias relações de homens (e mulheres) entre si e destes com a natureza; é não só separar os homens (e mulheres) da natureza como, também, separá-los entre si, individualizando-os (PORTO-GONÇALVES, 2011, p.39).

A geografia como um saber estratégico (LACOSTE, 2012) é uma das ciências que podem reproduzir o discurso colonialista, evidenciado na escassez de estudos que abordam as problemáticas indígenas. É necessária a reprodução de conteúdos com a descolonização do pensamento (PORTOGONÇALVES, 2012), compreendendo a diversidade dos povos indígenas, fortalecendo a luta pela autonomia e desmistificando as dificuldades sociais e os conflitos presentes no território: "A rejeição dos índios ao sistema colonial significa não apenas a defesa de suas terras, mas de seus costumes, de seu gênero ou modo de vida, que seria a manifestação típica de uma sociedade no espaço" (AMPARO, 2012, p. 60).

\section{O TERRITÓRIO COMO DEFESA E RESISTÊNCIA DA IDENTIDADE SOCIAL}

\footnotetext{
${ }^{3}$ (Araújo, 2011, p.33, tradução nossa) "Os nativos seriam ingênuos e maliciosos, pacíficos e canibais, assim, romantizados e odiados."
} 
O território para os povos indígenas simboliza o modo de reprodução das suas culturas e visões de mundo. Além do valor material de autoconsumo e abrigo, há também o espiritual através das múltiplas cosmovisões agregadas a terra por cada povo:

Mais do que uma coisa ou objeto, o território é um ato e uma ação, uma rel-ação assim como um movimento de territorialização e desterritorialização dotado de ritmo e que pode se repetir e se exercer controle. Ou seja, a desterritorialização é o movimento de abandono do território, uma operação em linha de fuga, e a reterritorialiação é o movimento de construção do território (GUERRA, 2009, p. 18).

A maior parte das populações indígenas foram forçadas a esconder suas identidades e adaptarse ao modo de vida imposto pelos grandes proprietários de terra das regiões mais próximas de seu território para conseguirem se proteger. 0 medo da identificação e a ocultação das suas ancestralidades é uma realidade a quais muitos povos tradicionais ainda estão sujeitos. Os Xukuru de Ororubá, originários do Nordeste, por muitos anos viveram escondidos nas fazendas ou eram submetidos ao trabalho forçado (ARAÚJO, 2011), sendo identificados como caboclos. Foi através da reprodução oral das suas crenças e cultura que se constituiu o seu modo de resistência. Eles só conseguiram a homologação das suas terras em 2001, por meio das retomadas de território e da luta de figuras importantes como a do Cacique Xicão.

As retomadas de territórios são uma das principais formas de resistência indígena. 0 povo Tapeba, localizado no município de Caucaia no estado do Ceará, há 35 anos luta pela demarcação das suas terras. Através das retomadas e da articulação com outros povos indígenas do estado, eles resistem e buscam reproduzir a sua cultura através do investimento na criação de escolas e movimentos culturais. Assim, as populações originárias constroem suas multiterritorialidades (HAESBAERT, 2004), estando em constante processo de defesa dos seus territórios e continuidade das suas culturas.

As problemáticas presentes na demarcação dos territórios não se restringem apenas ao processo de reconhecimento da terra como sendo indígena, mas também nos limites estipulados para cada povo. Os territórios estabelecidos pelo Estado, na maior parte dos casos, sofrem reduções em sua área, ficando a comunidade comprimida em porções de terra demarcadas de acordo com os interesses ruralistas de expansão na região.

É necessário então

um movimento mais amplo dos povos indígenas no Brasil em busca da ampliação dos limites de suas terras, que por terem sido demarcadas em outro momento e contextos políticos não contemplaram, na maioria das vezes, as reivindicações dos povos. (GUERRA, 2011, p.12).

Os privilégios obtidos pelos grandes proprietários de terra não são expressos apenas na redução dos territórios indígenas no processo de demarcação, mas também no ato de 
"Ceder" a terra, principal apelo dos índios, foi, em muitos casos, uma medida indigenista necessária para mantê-los afastados de outras. Assim, mesmo antes do SPILTN, já existiam registros de terras reservadas aos índios, ainda que por diferentes esferas e em diferentes contextos (AMPARO, 2012, p. 62).

O conceito de assentamento em um determinado território foi imposto aos povos nativos pelo colonizador e posteriormente pelo Estado nacional. As sociedades originárias eram caracterizadas pela sua mobilidade e por serem nômades. A ideia de estabelecimento, assim como a noção de uso produtivo das terras, tem como objetivo inserir a concepção de desenvolvimento econômico nas comunidades, como forma de extrair os recursos produzidos nas terras indígenas e obter lucro para o mercado. Contudo, o conceito de território estabelecido pelas comunidades tradicionais é diferente da adotada pelo modelo colonizador e etnocêntrico:

[...] as demandas dos povos indígenas não podem ser entendidas conforme um modelo de produtores rurais independentes, justamente por configurar um grupo étnico, que partilha tradições culturais mantendo relações simbólicas com um território que identifica como seu (GUERRA, 2011, p.8).

No entanto, é necessário compreender que o direito à auto identificação e reconhecimento de um povo não deve se limitar a um único modo de vida. A identidade não deve ser algo mecanizado e restrito a características determinadas por uma sociedade que ainda é colonialista. A discriminação contra os povos indígenas é válida também na deslegitimação de comunidades por adotarem noções capitalistas de produção e reprodução.

A imagem do índio brasileiro continua sendo marcada por uma visão extremamente romântica, a qual remete exclusivamente ao índio idealizado e selvagem, habitante das aldeias e florestas, onde em suposta "harmonia" com a natureza, vive da caça e da pesca, como se o tempo tivesse passado para nós e não para eles. Esta imagem, porquanto, ainda exista, em alguns casos, atua, porém, como cortina de fumaça sobre a situação do índio contemporâneo (AMPARO, 2013, p. 37).

A autonomia dos povos indígenas verifica-se no direito a adoção do seu próprio modo de vida, seja de modo individual seja por meio da comunidade, e no reconhecimento da presença de povos originários em ambientes diversificados, como a inserção de comunidades indígenas no meio urbano (AMPARO, 2013). Ao se assumir a diversidade desses povos e os diferentes ambientes em que estão inseridos, são evidenciados os reais problemas aos quais eles encontram-se expostos. Assim como no meio rural, em espaços urbanos os índios também estão sujeitos a preconceitos e marginalização. Por não satisfazerem o estereótipo do indígena idealizado pelo colonizador e reproduzido pela sociedade, esses povos que vivem no meio urbano são suprimidos e criminalizados.

A vinculação da identidade indígena a um modo de utilização e convivência com o território determinado por sujeitos não indígenas desencadeia outra forma de violência. 0 reconhecimento e a identidade de um povo não deve ser visto como algo frágil e modificado de acordo com moldes impostos por uma sociedade que ainda utiliza a "lente" moderno-colonial como forma de perceber o mundo. 0 movimento indígena não é vulnerável a ponto de ser deslegitimado de acordo com o 
ambiente escolhido pelos seus protagonistas para a sua reprodução física e cultural ou pela adoção de características originárias de outros povos. A resistência está na autonomia e direito à identificação do povo como indígena.

\section{A INCÔMODA QUESTÃO AMBIENTAL}

A identificação das comunidades tradicionais com o território também compreende as questões ambientais. A construção da espiritualidade das sociedades originárias, no caso do Ceará é estabelecida por meio da convivência com o ambiente no qual eles vivem. Os Tremembé de Queimadas, povo indígena localizado no município de Acaraú, no Ceará, possuem uma forte ligação com o caju. A castanha de caju é utilizada como forma de subsistência tanto para a alimentação da comunidade, quanto para as práticas artesanais. A relação dessas comunidades com o ambiente configura-se também como uma forma de adaptação ao local. Além dos Tremembé, os Potyguara têm a sua espiritualidade estruturada na Caatinga e os Tapeba retiram suas crenças do mangue, ambos os povos estão localizados no estado do Ceará. Assim, a cultura e as cosmovisões de grande parte das comunidades indígenas são construídas a partir do respeito com o meio ambiente.

Por conta da grande agrobiodiversidade presente na maior parte das terras indígenas, o interesse e a conseqüente promoção de conflitos originados por não índios é constante. Sobre as terras indígenas, Guerra (2011, p. 1) destaca:

A maior parte dessas terras concentra-se na Amazônia Legal, despertando o interesse mundial, principalmente pela riqueza da biodiversidade dessa região, cujo conhecimento tradicional está nas mãos das populações que vivem e manejam, ancestralmente, seus ecossistemas (GUERRA, 2011, p.1).

Assim, há o crescimento dos conflitos nos territórios que possuem características favoráveis para a instalação de grandes produções agrícolas. De acordo com a necessidade do mercado, determinadas porções de terra tornam-se mais interessantes que outras. 0 agreste pernambucano foi uma das regiões que presenciou as transições dos diferentes ciclos econômicos, em especial com a implantação da agropecuária e das produções de café (CORREIA, 2005). As terras com grande agrobiodiversidade ou que detêm recursos essenciais, como a água torna-se espaços de poder e de disputas, deixando os povos que residem no local vulneráveis aos ataques dos posseiros e dificultando o estabelecimento das comunidades indígenas em seu próprio território. A violência promovida pelo controle do território pode manifestar-se através dos impactos ambientais que afetam a saúde e os sistemas de subsistência indígena. Guerra (2009, p.8), ao estudar sobre os Kalapalo, povo indígena localizado no Mato Grosso do Sul, ressalta que:

Nas últimas décadas esta região configurou-se como uma nova fronteira agrícola para a produção de arroz e soja, principalmente, para atender o mercado externo. Este modelo de desenvolvimento econômico regional tem sido responsável por grandes impactos ambientais e sociais em várias regiões do Brasil e no Estado do Mato Grosso 
sua intensidade tem sido preocupante. Pois, todo o entorno do parque vêm sendo desmatado para dar lugar às lavouras de soja (GUERRA, 2009, p.8).

A água é uma das principais motivações para os conflitos pela terra. Particularmente em regiões como o semiárido nordestino, que possui limitadas áreas com recursos hídricos, a problemática da água acarreta em uma intensificação na luta pelos territórios. Para as comunidades indígenas, somada às dificuldades na obtenção de água e da implantação de um saneamento básico adequado, há a constante pressão política e dos fazendeiros que possuem interesse nos recursos hídricos da região. Assim como a natureza, os povos indígenas são colocados na condição de objetos a serem manipulados de acordo com as necessidades dos que detêm o poder, "apresentando-se a Europa por civilização e o europeu por civilizado, como vimos; ao índio e sua aldeia ou assentamento não se poderia dar outro status se não o da natureza." (AMPARO, 2012, p.42).

A particularidade de cada povo também é expressa no trato com o ambiente em que convivem. Apesar da agricultura indígena ser constantemente vinculada à forma de cultivo ecológico, as populações não necessariamente adotam a agroecologia como modo de subsistência (ARAÚJ0, 2011, p.9). Ao se estabelecer relações com outros povos, são inseridas outras visões de mundo nas comunidades, deixando heranças que podem afetar toda a cultura de um povo. Por meio de estudos sobre os Xukuru de Ororubá, Araújo (2011) estabeleceu a relação entre os modos de produção adotados no território antes da homologação pelos Xukuru, e a atual configuração territorial instituída por esse povo, entendendo que "entre os Xukuru há uma mentalidade ligada à agricultura convencional diretamente influenciada pelos anos de plantação em escala para as indústrias de processamento de alimentos que funcionavam e eram direcionados para a cidade mais próxima Pesqueira" (ARAÚJO, 2011, p. 10).

Assim, é perceptível a influência que exerce o contexto histórico e a cultura de uma região na convivência entre diferentes comunidades. Isso não invalida a identidade de um povo, mas insere novas visões de mundo e formas de lidar com a terra que podem não ser necessariamente benéficas para o ambiente. De acordo com Araújo (2011) "junto com a perda de seus territórios e destruição dos ecossistemas e paisagens, comumente encontramos hoje métodos de cultivo e criação de animais muito semelhantes aos das regiões onde estão inseridos" (ARAÚJO, 2011, p. 10).

A construção da imagem do índio como inferior por sujeitos não indígenas é refletida na percepção das suas práticas e modos de subsistência. Diversos povos indígenas ao relacionar-se com a terra integram a sua espiritualidade e cosmovisões nas práticas agrícolas, produzindo o necessário para a sua continuidade. Com o modo capitalista de produção, e o investimento em uma monocultura de alimentos que tem como prioridade a mercantilização do produto, sem alimentar quem produz (PORTO-GONÇALVES, 2006), os saberes originários foram postos de lado e vistos como incapazes de sustentar uma comunidade, porém 
[...] investigaciones dedicadas a describir y analizar las prácticas agrícolas y la lógica de los pueblos nativos y campesinos han presentado otro cuadro. Un conjunto de antropólogos, geógrafos, arqueólogos e historiadores han demostrado, por un lado, la capacidad productiva de los sistemas nativos, los cuales han sustentado incluso grandes aglomerados humanos. (ARAÚJO, 2011, p.15) ${ }^{4}$

Os povos tradicionais demonstram que é possível conviver com a natureza, retirando dela o necessário para sobreviver e reproduzir a sua cultura, sem causar grandes impactos ao meio ambiente. Mesmo com características, inseridas por outros povos, de formas de produção que causam efeitos negativos no meio natural, como a agropecuária nos Xukuru, a busca por alternativas e a retomada do conhecimento ancestral para auxiliar no trato com a terra e na preservação ambiental do território é uma possibilidade presente na demanda do movimento indígena atual.

[...] Os agroecossistemas tradicionais demonstram na prática como tal base pode ser apropriada, trabalhada, inovada e respeitada pelas sociedades. São exemplos de como uma cultura e seu ambiente local têm co-evoluído com o tempo através de processos que balanceiam as necessidades das pessoas, expressas como ecológicas, tecnológicas, culturais e socioeconômicas (ARAÚJO, 2011, p.15).

\section{A CULTURA COMO CHAVE EXPLICATIVA PARA COMPREENDER A COMUNIDADE}

A construção ideológica da imagem dos povos originários é refletida na reprodução de nomenclaturas de caráter colonialista, naturalizando uma linguagem que exclui ou apresenta o índio como coadjuvante do passado brasileiro, "[...] fugindo de velhos sofismas e discursos passadistas, marcados por um ambientalismo elitista, que deixa de considerar o indígena em sua condição histórica para naturalizá-lo junto à natureza" (AMPAR0, 2013, p.35).

A luta e afirmação da identidade também são representadas por meio da composição de um vocabulário que atenda as particularidades de cada povo. A criação de novas formas de se expressar, que não tenham sido determinadas por um dicionário com bases eurocêntricas, assim como o resgate da língua nativa dos povos originários, torna-se uma das maneiras responsáveis pela resistência e sobrevivência da cultura. Porto-Gonçalves (2009) ao realizar um estudo sobre a palavra Abya-Ala, proposta pelos povos indígenas como forma de substituir o termo América, demonstra o significado político e identitário que uma palavra possui, assim como a importância da autonomia de um povo para dominar o seu próprio vocabulário.

Não olvidemos que dar nome próprio é apropriar-se. É tornar próprio um espaço pelo nome que se atribui aos rios, às montanhas, aos bosques, aos lagos, aos animais, às plantas e por esse meio um grupo social se constitui como tal, constituindo seus mundos de vida, seus mundos de significação e tornando seu um espaço - um território. A linguagem territorializa e, assim, entre América e Abya Yala se revela a tensão de territorialidades (PORTO-GONÇALVES, 2009, p.29-30).

\footnotetext{
4 Destacamos que investigações dedicadas a descrever e analisar as práticas agrícolas e a lógica dos povos nativos e camponeses tem demonstrado outro quadro. Um conjunto de antropólogos, geógrafos, arqueólogos e historiadores apresentam, por um lado, a capacidade produtiva dos sistemas nativos, nos quais tem sustentado grandes aglomerados humanos.
} 
Muitas comunidades vêm adotando os princípios do bien vivir com o objetivo de substituir a noção de desenvolvimento. É através da adesão desses preceitos que os povos originários constroem suas próprias formas de lidar com o território de modo sustentável, auxiliando na integração das suas cosmovisões com as práticas adotadas para a reprodução física e cultural.

Os povos indígenas possuem um extenso acervo cultural, e a transmissão da história oral sempre se caracterizou como uma das principais formas de conservação dos saberes originários. Por meio da construção de escolas indígenas e da inserção de cursos voltados para esses povos nas universidades, há a apropriação do conhecimento, conscientizando as próximas gerações. 0 fortalecimento da educação no movimento indígena permite a introdução da espiritualidade e dos rituais em ambientes diversificados, familiarizando a população juvenil às diferentes visões de mundo e a importância de elementos que representam as crenças dos povos originários, como o ritual do toré e a relação com a jurema ${ }^{5}$. A resistência é ensinada por meio de cantos e de ambientes escolares, da apropriação da linguagem e preservação dos rituais. A aculturação dos povos originários é um mito, um conto produzido pelo pensamento moderno-colonial baseado em preconceitos e desconhecimento da dimensão da cultura indígena.

\section{CONSIDERAÇõES FINAIS}

O fortalecimento da luta indígena está na autonomia desses povos, fazendo com que eles sejam protagonistas de sua própria história. Os conflitos presentes em seus territórios têm sua estruturação em ideologias e interesses de não indígenas, refletindo nas problemáticas sociais dessas comunidades, que afetam setores básicos como a saúde e educação. A cultura e o resgate das práticas tradicionais são um dos principais meios de resistência, transmitidos em ambientes diversificados de modo a atender a demanda juvenil do movimento indígena.

A articulação da luta dos povos originários também é identificada na produção de estudos voltados para as necessidades dessas comunidades que busquem compreender as diversidades e particularidades de cada povo, largando de mão preconceitos e generalizações. A contribuição da geografia para a consolidação dos debates sobre a questão indígena, a partir de elementos essenciais como o território e a cultura desses povos, auxilia na produção de conteúdos que compreendam as diversas concepções de mundo, construindo discussões significativas para o movimento indígena e que também sirvam como forma de resistência e continuidade da luta.

\footnotetext{
${ }^{5}$ A Jurema é uma planta utilizada nos rituais indígenas, em especial no Toré, ocorrendo em algumas ocasiões o seu consumo. Nela estão atrelados conhecimentos originários e espiritualidades.
} 


\section{REFERÊNCIAS}

AMPARO, S. dos S. Indigenismo como processo de territorialização: introdução ao estudo sobre a forma das aldeias indígenas brasileiras. Revista EDUCAmazônia (Educação Sociedade e Meio Ambiente), Ano 5, vol. VIII, jan-jun, Humaitá, AM, 2012.

AMPARO, S. dos S. Questão indígena como questão urbana: notas para a construção de uma problemática geográfica. Ensaios de Geografia. V. 1, no. 2, 2013.

ANDRADE, M. C. de. A terra e o homem no nordeste: contribuição ao estudo da questão agrária no Nordeste. São Paulo: Cortez, 2005. ARAÚJO, A. L. O. Una mirada Agroecológica en la pisada Xukuru do Ororubá: un presente de posibilidades. 2011. Dissertação (Maestría) Universidad Internacional de Andalucía. Universidad Pablo de Olavide. Universidad de 181 Córdoba. Maestría en Agroecología un Enfoque para la Sustentabilidad Rural. Córdoba, 2011.
GUERRA, Emerson. A luta dos kalapalo pela reterritorialização em naruvutu. (mimeo) Universidade Federal Fluminense, Niterói, RJ, 2009.

. Gestão territorial na terra indígena xakriabá e a geopolítica das retomadas. Revista Geográfica de América Central, vol. 2, Universidad Nacional Heredia, Costa Rica, 2011.

HAESBAERT, R. $O$ mito da desterritorialização: do "fim dos territórios" à multiterritorialidade. Rio de Janeiro: Bertrand Brasil, 2004.

LACOSTE, Yves. A geografia - isso serve, em primeiro lugar, para fazer a guerra. Campinas, SP: Papirus, 2012.

PORTO-GONÇALVES, C. W. Entre América e Abya Yala - tensões de territorialidades. Revista Desenvolvimento e Meio Ambiente, $\mathrm{n}$. 20, jul./dez. Editora UFPR, 2009. O desafio ambiental. Rio de Janeiro: Record, 2004. 